\title{
Designing Educational Software: The Case of Grid Algebra
}

\author{
Dave Hewitt ${ }^{1}$
}

Published online: 3 May 2016

(C) Springer International Publishing 2016

This article discusses some of the key ideas which lie behind the design of the software Grid Algebra. ${ }^{1}$ In doing so, it offers an example of how design can tap into some deeprooted knowings that all learners have, be based upon ways in which fluency has been achieved within our everyday lives and, more specifically within the topic of algebra, how known misconceptions can be addressed or avoided. The software offers an original and intuitive approach to teaching algebra, a topic found by many teachers to be 'hard to teach'.

Following discussion of background issues, I gradually introduce some of the key design features of the software and how these relate to established difficulties learners experience when learning algebra. This is followed by articulation of three frameworks, which underpin the whole design. I end by considering some of the limitations of the software, as well as summarising the features which make this an intuitive approach to the early learning of algebra, before raising questions not only related to the design of this particular software but more general ones about the design of a range of resources which could be based upon the frameworks used here.

\section{Background}

There has been a considerable amount of research in the decades leading up to the end of the twentieth century, research which has indicated difficulties learners experience with algebra (for example, Küchemann 1981; Booth 1984; Filloy and Rojano 1989; Herscovics and Linchevski 1994; MacGregor and Stacey 1997). The influential

\footnotetext{
${ }^{1}$ Available from the UK Association of Teachers of Mathematics (ATM): http://www.atm.org.uk/Shop/GridAlgebra-Single-User-Licence/sof071. Some videos describing its use can be found on YouTube (search for 'Grid Algebra').
}

Dave Hewitt

d.p.hewitt@lboro.ac.uk

1 Mathematics Education Centre, Loughborough University, Schofield Building,

Loughborough LE11 3TU, UK 
Cockcroft report in the UK (DES 1982) indicated that, "algebra is a source of considerable confusion and negative attitudes among pupils" (p. 60) and, as teachers, we want to make sure that, "algebra is not a meaningless game with 26 letters" (Freudenthal 1973, p. 290; his emphasis). The difficulties include how the equals sign is viewed (Kieran 1981), the meaning given to letters (Küchemann 1981), the reading of formal mathematical notation (Kirshner 1989) and the need to treat an algebraic expression as an object as well as a process (Booth 1984; Tall and Thomas 1991).

Studies have shown that working with letters in a meaningful way can be achieved by relatively young learners (Carraher et al. 2001), and so the issue arises whether adolescents' difficulties with algebra may not lie solely with the learners themselves, but also with teaching approaches which impact negatively on their success with algebra (Brizuela and Schliemann 2004). Some teaching practices are not helpful when making the shift from numerical work to algebraic activity. These include: the almost exclusive use of arithmetic statements which have only a single number on the righthand side of the equals sign; the use of calculators where pressing the 'equals' button on a calculator results in a single numerical result; always expecting learners to carry out calculations when faced with an arithmetic expression. McNeil and Alibali (2005) offer a change-resistant account where such entrenched operational patterns persist and contribute to learners' difficulties with equations.

Different images have been offered to try to assist learners with algebra, including the use of cups and tiles (Caglayan and Olive 2010), an empty number line (Dickinson and Eade 2004), a spreadsheet (Ainley 1999) and a balance (Vlassis 2002). Each of these images can offer some support for learners, but none offers the opportunity for learners to work directly with standard mathematical notation. As a consequence, there would need to be a separate learning process to learn how to write and read standard notation. There have been attempts to do this when using some of these images (da Rocha Falcao 1995; Bills et al. 2006), but the journey to using standard notation remains a far-from-straightforward transition.

Although learners are quite capable of creating their own notation (Steffe and Olive 1996), the "inverse process of interpreting symbols to unfold mathematical concepts challenges all learners" (Sáenz-Ludlow and Walgamuth 1998, p. 153). This is reflected in the fact that using standard notation is sometimes seen as the final part of generalising tasks - for example, finding a rule for a geometric pattern (Warren 2006). The sometimes unconventional notational form with which a learner writes a rule carries with it her or his own awareness and embodied experience of working on a problem (Radford 2002); as such, the form of the notation, albeit non-standard, matters. So why would a learner feel it necessary to write it in a different way, solely because a teacher asks them to do so? In contrast, Dörfler (2006) suggests seeing notation as an example of an object, or diagram, through which we learn mathematics. As such, notation is not an afterthought, but rather an inherent part of mathematical activity.

The software Grid Algebra is designed to help learners become fluent with standard notation while developing their algebraic abilities toward, among other things, solving linear equations. Behind the design lies a perspective on algebra that stresses properties of operations and attending to mathematical structure, with or without the inclusion of letters. Gattegno (1988) describes algebra as essentially concerning "operations upon operations" (p. 77). Within a school arithmetic context, this would involve a shift of attention from carrying out operations (in order to do arithmetic) to attending to the 
operations themselves and operating upon those operations. For example, becoming aware of order, inverse and equivalence of operations can be used in general arithmetic situations, such as multiplying out brackets or solving equations. The sense of generality and focus upon operations (rather than on numbers) brings with it a sense that particular numbers are irrelevant and consequently letters can be introduced and used with relatively little conceptual difficulty for learners.

Grid Algebra calls upon mathematical notions such as order and inverse, which are known intuitively through moving objects and making journeys in their daily lives. The software makes use of the idea of movement on a grid of numbers to create and work with expressions written in standard notation. Elsewhere (Hewitt 2014b), I have described the intricate relationship between the intuitive world of physical movements on the grid and the abstract world of mathematical symbolism with which the movements are associated. Learners can shift between one world and the other while developing their confidence in working with the mathematical notation.

The software has enabled relatively young learners (9-10 years old) to go from never having met the use of brackets in a mathematical context, nor a division line in notation other than the division sign $\div$, nor a letter in an algebraic context, to solving linear equations within just three lessons (Hewitt 2012). At the end of the third and final lesson, learners were offered a choice of one of two sheets to complete; the first had a series of equations to solve (as in Fig. 1), while the second also had equations to solve but these were placed within the visual context of movements around the Grid Algebra grid (see Fig. 2). More explanation of these movements will be given later.

Figure 1 shows the work of a pair of learners from their mixed-ability class of 910 year olds, which was completed at the end of the third lesson. One thing to note is that this sheet contained all their working and, as such, they were able, as were many others, to solve these equations without any intermediate steps.

One effect of using the software was that learners become very familiar with standard notation and were used to reading order within this notation and also identifying inverse operations in the appropriate order as well. Even the weakest learner in the class was able to write solutions to equations on paper involving up to four operations where the challenge on paper included a visual of the Grid Algebra grid (Fig. 2).

The design of the software is centred around two main aspects: (a) it tries to address some of the standard misconceptions related to learning algebra; (b) it is rooted within strong theoretical frameworks which inform the nature of the feedback learners receive, how learners gain fluency with standard notation within a relatively short amount of time and how the design accesses and formalises intuitive notions which are deeply embedded within all learners. At this point, I will say something briefly about each of the three theoretical frameworks I drew on. But I will leave more detailed discussion until the reader has already become aware of some of the functionings of the software, which will be done through discussing some standard misconceptions learners have with algebra.

Question 6:

Question 7:

Question 8:

Question 9: 10,6

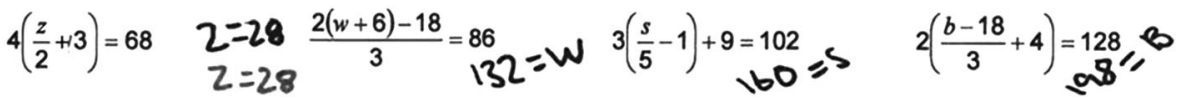

Fig. 1 Solving linear equations by a pair of 9-10-year-old learners after three lessons 
Work out the number value of the letter in each case
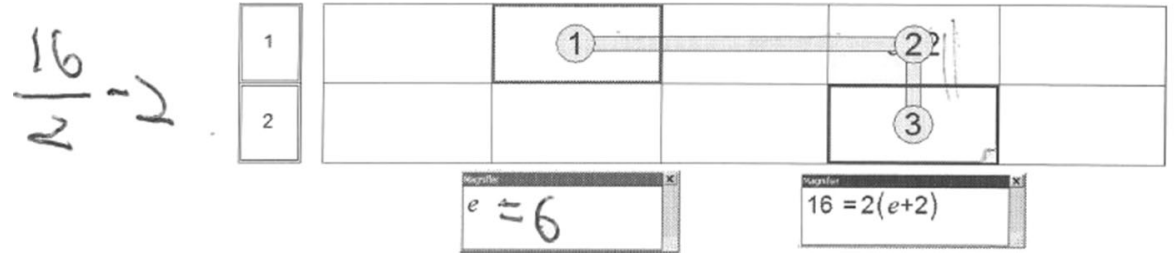

Fig. 2 Solving a linear equation by the weakest learner in the class with imagistic support based upon Grid Algebra

The first framework is arbitrary and necessary (Hewitt 1999, 2001a, b), which divides the mathematics curriculum respectively into those things where there is choice and which have been socially agreed (names and conventions), and those things which can be argued that they must be how they are (properties and relationships). I have argued elsewhere (Hewitt 1999) that learners need to be informed of what is arbitrary and Grid Algebra does this by providing the way in which mathematical expressions are written in formal notation. Also, learners do not need to be informed of what is necessary and so Grid Algebra does not provide any answers or carry out any calculations. Instead, tasks are offered from which learners can become aware of mathematical properties and relationships.

The second framework is that of subordination (Hewitt 1996). This concerns the way in which learners have to use the formal notation provided by the software, despite their attention being focused elsewhere and even though they may not be confident with interpreting that notation. The way in which the software provides neutral but interpretative feedback (Edwards 1998) allows the learner to revaluate her or his interpretation of the notation and to develop confidence and fluency with that notation through its subordinated use in the given tasks.

The third framework is embodied cognition (Varela et al. 1993). This concerns the claim that mind and body are not separate and that many of the ways in which we think about things have roots within bodily experience. Grid Algebra accesses deep experience all learners have encountered through movement. Through making a strong association between, for example, the notions of order and inverse (a) as they are experienced within movement and (b) as they can be expressed within mathematical activity and notation, learners' new understanding of mathematical situations is supported through their already established, albeit implicit, knowing within the context of movement.

More detail about each of these frameworks will be provided and examples of how they have informed the design of Grid Algebra will be given later in this article. I have done this because the depth of how each has informed the design is best seen once the reader is already aware of the key functionality built into the software. This functionality will be developed gradually through not only a description of the grid itself and movements within it, but also through how the design has taken into consideration some of the standard misconceptions that many learners experience when learning algebra.

It is important to realise that the design is not just restricted to the functionality of the software, but also includes some of the tasks envisaged in conjunction with the 
software use. The functionality of the software provides certain affordances and constraints (Greeno 1994) and as such allows certain activities to take place. However, envisaged tasks also inform the design of the functionality. So, tasks and functionality are interlinked. Indeed, Grid Algebra has many computer-generated tasks built into the software, although only a few are mentioned here. There is also an Interactive mode where a teacher or learner can create her or his own explorations on the grid.

Before starting on the two aspects mentioned above, I will address the design of the grid and its related symbolism, both of which form the basis of all subsequent activity. In the initial discussion of design issues, the examples I offer relate to numbers and it is only later on that letters show up. There are a number of reasons why I have done this. Firstly, it gives a sense of the gradual shift in attention, from numbers to operations and letters, for learners as they engage in activities. The second relates to the way algebra is concerned with "operations upon operations". As I discuss various design issues, there is a key moment when attention shifts from numbers on the grid to operations which establish relationships between numbers on the grid. Thus, the design of the software is such that the focus is on operations rather than numbers per se.

\section{The Structure of the Grid}

School algebra is based upon generalisation of the four arithmetic operations; addition, subtraction, multiplication and division. Figure 3 show part of the first six multiplication tables, with the numbers in the left-hand column indicating to which tables they belong.

On starting up the software, the grid is static and empty, but there is a Numbers button within a toolbox which, when pressed, will fill up the grid with numbers. The default is that it will fill up the grid as in Fig. 3. Slider bars can be seen and used to view other multiplication tables if scrolled down, or further numbers within each table if scrolled to the right. The figure shows six rows, but a smaller number of rows can be on

\begin{tabular}{|c|c|c|c|c|c|c|}
\hline 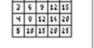 & 1 & 1 & 2 & 3 & 4 & 5 \\
\hline \multirow{5}{*}{ 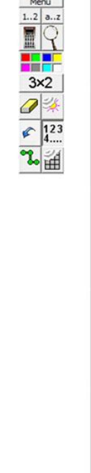 } & 2 & 2 & 4 & 6 & 8 & 10 \\
\hline & 3 & 3 & 6 & 9 & 12 & 15 \\
\hline & 4 & 4 & 8 & 12 & 16 & 20 \\
\hline & 5 & 5 & 10 & 15 & 20 & 25 \\
\hline & 6 & 6 & 12 & 18 & 24 & 30 \\
\hline
\end{tabular}

Fig. 3 Part of the first six multiplication tables 
view if that is desired, right down to a single row. Not all numbers have to be on view at any one time. There is a Rubber which can rub out any particular number or collection of numbers.

It is also possible to start with a blank grid and choose a number from a Number Box and drag that number into a cell. The number is only accepted into a cell if it is in the times table for that particular row. So, in an otherwise blank grid, the number 12 can be placed anywhere in rows $1,2,3,4,6$ or 12 . If it is placed in a different row, then it appears in a light grey colour with a No Entry sign in the cell. This allows someone time to consider why it is not being accepted and then, on the next click of the mouse, the number will drift off into a Bin which appears on the screen. When the grid is empty, any number can be dragged from the Number Box into any cell in an appropriate row. There is a choice of allowing just positive integers only in the Number Box or to allow negatives as well.

With an empty grid, the value of each cell is undetermined and so an icon of an empty grid appears on the top-left of the screen to indicate this. When a number, such as 12 is placed in a cell the entire grid is then defined: there is no longer any choice as to which number should go into any other cell. To indicate this, the grid icon becomes full of numbers. If the Numbers button on the toolbox were to be pressed now, it will fill the grid with numbers based upon the fact that 12 is in that particular cell. Thus, if 12 were in row 4 (the four times table), then the number to the left of it would be 8 and the number immediately to the right would be 16 . The number above it would be the equivalent number in the three times table, namely 9, and below it would be the equivalent number in the five times table, i.e. 15.

There are many tasks which can be done at this stage to help learners become familiar with the structure of the grid. For example, a grid full of numbers can have one number rubbed out and a learner has to drag the appropriate number into that blank cell. Or the grid can be blank except for a number in one cell. Someone can Highlight another cell on the grid (colours are available from the toolbox) and the task is for a learner to decide what number must be in that highlighted cell and to drag the specific number from the Number Box into that cell. Such tasks are significant, as the explicit 'outer' meaning (Tahta 1981) is about placing the correct number into a specific cell. However, the implicit 'inner' meaning concerns shifting a learner's attention away from numbers and on to arithmetic relationships between the cells. In order to carry out such tasks, a learner begins to work out arithmetic operations which link the position of the given number to the position of the highlighted cell, as a pre-cursor for what is to follow.

\section{Movement on the Grid}

School algebra places an emphasis upon arithmetic operations rather than upon numbers themselves. For example, 'multiplying out brackets' depends upon a property of operations (the distributive law), not of numbers. Thus, to work towards algebraic activity requires attention to be placed on operations. Initially, the grid tends to stress numbers, as it is these which are seen. However, operations exist in the relationships between the various numbers in the grid. For example, if I were to look at the number 1 and consider what I can do to 1 to get to 2 , I can either think of this as $1+1$ or $1 \times 2$. The verb 'to get to' can also be interpreted visually as a movement from the number 1 in the 
grid to get to the number 2 in the grid. This gives a sense of making a journey on the grid with operations being the journeys taken from one number on the grid to another number on the grid. ${ }^{2}$

Both the options of $1+1$ and $1 \times 2$ can be accommodated, since multiplication tables can be seen both horizontally and vertically. Thus, a decision was taken to view the horizontal as additive and the vertical as multiplicative. This is an arbitrary decision, but what is important is that once the decision is taken, it remains consistent in the design of the software. So operations concern both the arithmetic relationship between numbers and the physical movement on the grid from one cell to another. The software allows both of these perspectives to occur simultaneously, through a person being able to click on the number 1 cell and physically drag this across either horizontally to the number 2 cell on the right, or vertically to the number 2 cell below (see Fig. 4). The first movement will reveal the expression $1+1$ in the cell to the right of it (which had the number 2 in it), while the second movement will produce the expression $1 \times 2$ in the cell below it (which also had the number 2 inside it). In this way, the software changes the static grid (with a focus on numbers) into a dynamic, interactive one (with a focus on movement and operations).

Movement to the right is shown consistently as addition, no matter in which row. The particular row is significant, however, since moving one cell to the right in row 4 will result in adding four and not just one, since it is in the four times table. The inverse operation to addition is subtraction and this is matched with the inverse movement of moving to the left rather than the right. This means that learners' intuitive sense of inverse within movement can assist the learning of inverse within arithmetic operations.

Downwards movement is consistently interpreted as multiplication. When starting from the one times table, moving downwards to any other times table is straightforward. For example, moving down from 5 in the one times table to 30 in the six times table would result in $5 \times 6$ being shown (see Fig. 4). Consideration needs to be given to other vertical movements which do not start in the one times table. For example, starting with the 12 in the three times table, and dragging it down to the number 24 , will show $12 \times 2$. This has involved a downwards movement of three rows to produce $x 2$ whereas it would have been only a downwards movement of one row if it has started in row 1 (the one times table). There is a significant pedagogical issue here to help learners become familiar with multiplication on the grid. Knowing which multiplication table a given number is in is important and so this is one reason why there is an additional left-hand column added on the grid to label the multiplication table for each row.

A key design issue was deciding what would happen if someone wanted to drag a number from the three times table to the four times table, say. This would mean multiplying by $1.3^{\circ}$ and other possible multiplications could involve decimals with a greater number of recurring digits. An alternative would be representing such a multiplication as $\times \frac{4}{3}$. This would avoid the messiness of having numbers with several decimal places and stay more in touch with the particular rows involved. However, there would be other issues involved such as whether such fractions get simplified or

\footnotetext{
${ }^{2}$ In fact, it is really about the relation of one cell on the grid to another cell. The awareness that it is about cells rather than particular numbers in those cells brings with it a sense of generality which allows letters to be introduced in an intuitive way. This is discussed later.
} 


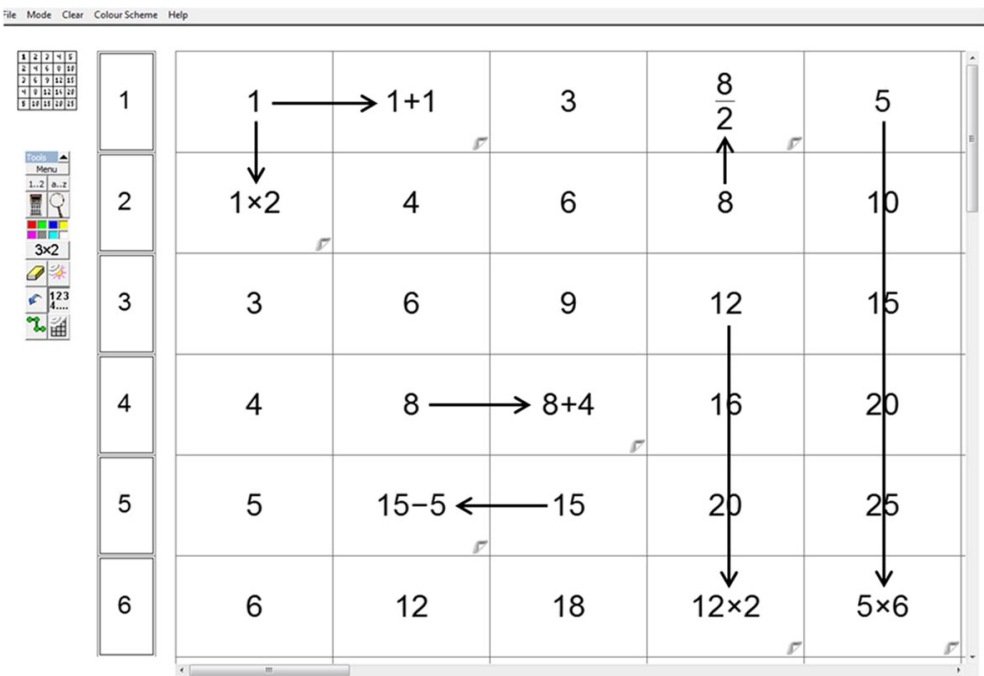

Fig. 4 Movements made on the grid and the simultaneous and consequential production of expressions

not. Clearly, the example above of moving from 12 to 24 is arguably more naturally represented as multiplying by 2 and not by $\frac{6}{3}$. So, should other movements, such as moving from the four- to the six times table, be represented as $\times \frac{3}{2}$ rather than $\times \frac{6}{4}$ ? There is no 'correct' answer to such designs issues and the final decision was based upon pedagogical considerations rather than on purely mathematical considerations.

I saw this software being used in primary as well as secondary schools and with learners with a wide range of attainment. I also wanted attention to be on generalities concerning operations and, as such, I did not want learners to be distracted by trying to work out why certain non-integer numbers appeared. Consequently, I decided that a downwards movement which resulted in multiplication by a non-integer would not produce an expression at all. Such movements result in an ' $\mathrm{X}$ ' appearing temporarily. This means that all expressions produced on the grid are made up of operations with integers, which has the added advantage of allowing a learner to see that if they start with the two times table then as they drag downwards it is only every second row that they get an expression appearing (see Fig. 5).

\begin{tabular}{|c|}
\hline 3 \\
\hline 6 \\
\hline 9 \\
\hline 12 \\
\hline 15 \\
\hline 18 \\
\hline
\end{tabular}
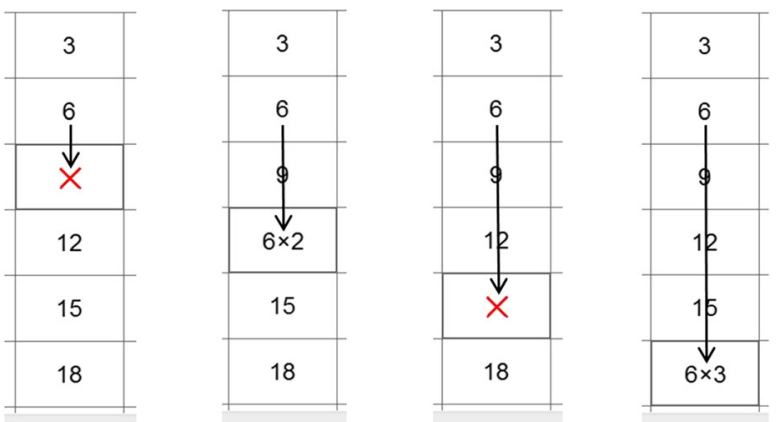

Fig. 5 The sequence of what is shown when a number from the two times table is dragged downwards 
As with addition and subtraction, division is produced by carrying out inverse movements to those for multiplication. Thus, division is an upward movement and is represented symbolically with the division line rather than the symbol $\div$ (see Fig. 4 for an example). The decision for this is that the software heads towards work with expressions using letters and, as such, the division line notation is important for what is to follow.

The introduction of movement is key to shifting attention from numbers to operations. With the focus on operations, the shift into algebraic activity begins.

\section{Difficulties with Algebra}

I now consider four well-researched sites of difficulty which learners encounter when beginning to learn algebra: process/object; introduction of letters; parsing expressions; the equals sign. For each of these, I briefly discuss some issues from literature before relating those to the design of the software.

\section{Process/Object}

It is common for younger learners to be asked to carry out arithmetic tasks where the focus is on developing the fluency to be able to add, subtract, multiply and divide. The emphasis is on carrying out a calculation correctly and a single numerical answer is the desired response. Learners come to expect answers to be a single entity and if something is stated which involves an operation, then this must be a question, not an answer. It is no surprise then that learners have difficulty seeing an expression such as $5+n$ as an answer. Instead, it is often viewed as a question and, in consequence, a learner might attempt to do something to it in order to make a single entity; for example by conjoining to produce 5n (Booth 1984; MacGregor and Stacey 1997). Falle (2007) argued that learners need to be exposed to arithmetic expressions in different 'unclosed' forms, where operation signs are still seen visually within the expression. She also felt there should be a greater emphasis on the structure and meaning of expressions. Sfard (1991) observed that an expression such as $3(x+2)-1$ needs to be viewed as an object in its own right, as well as a process to be carried out and Gray and Tall (1994) have described the ability to view expressions in this flexible way as proceptual thinking.

In Grid Algebra, a number can be dragged horizontally or vertically to create a new expression. That expression can then itself be dragged once again, so that another expression is formed from two operations (since it has been dragged twice). This can continue, so that expressions of some complexity can be created. Figure 6 gives an example of the number 36 being dragged several times to produce the expression $\frac{3\left(\frac{36+12}{2}-4\right)+18}{6}-2$. Each time one of the expressions is dragged, it is being treated as an object, one that can be clicked on and dragged somewhere else. This is different from how an expression might be treated if it were written on paper. The form of the expression serves a key purpose: it is a historical artefact which reveals the journey undertaken so far. Any simplification of this expression, through calculation or transformation, would destroy that information. So the form of the expression is of upmost significance. 


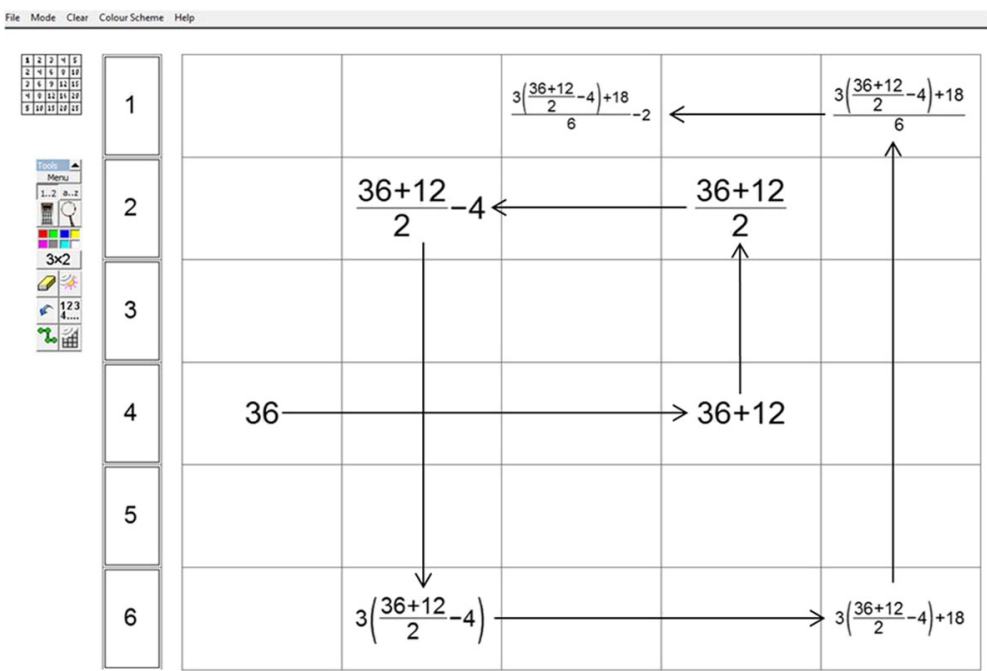

353637383

Fig. 6 The number 36 taken on a longer journey

Sfard and Linchevski (1994, p. 211) have commented that an "equation requires suspension of actual calculations for the sake of static description of relationships between quantities". Here, Grid Algebra stresses the relationships in terms of the operations carried out on the number 36 - and it is these operations which comprise the focus, rather than any desire for actual calculation.

A key task within Grid Algebra is to try to re-create such a journey when all expressions are rubbed off except for the original number (in this case, 36) and the final expression, $\frac{3\left(\frac{36+12}{2}-4\right)+18}{6}-2$. With such a task, the only clue for a learner is the form of the final expression and this becomes something which is to be examined carefully and has particular significance. So, unlike so many usual class tasks involving expressions with operations, there is a specific need not to carry out any of the calculations, but rather to see it as an object of significance in its own right. Further, as Falle (2007) has recommended, the task helps focus on the structure and meaning of the expression.

Koedinger et al. (2008) comment that, "Abstract representations, such as algebraic symbols, are concise and easy to manipulate but are distanced from any physical referents" (p. 366). The physical referents within Grid Algebra can be seen both as movements on the grid and as mathematical operations (Hewitt 2014b). The symbolic expression appears in the very place where the associated movement is made. The symbolism and referent are spatially closely related. Thus, there is a strong sense of physically acting upon the symbolic expression itself, of creating expressions through physically picking up an expression and moving it.

The combination of seeing an expression as an object, as mentioned above, along with other tasks, such as a learner being asked to drag a single number from the Number Box into the cell containing $\frac{3\left(\frac{36+12}{2}-4\right)+18}{6}-2$, allows learners to treat such an expression as a process as well as an object and so helps to develop what Tall (1991) describes as a proceptual way of thinking. 


\section{Introduction of Letters}

I have observed many a lesson where the learners appear quite confident with the work until a letter is introduced. Then, there are questions about what does that letter mean and why is it there. In a UK Year 8 class (12-13 year olds), there were two examples written on the board as follows:

$$
\begin{array}{lll}
\text { Example 1: } & x+3=9 & \\
\text { Example 2: } & x+7=10 & x=6 \\
& x=3
\end{array}
$$

When I asked one of the learners whether she understood what was written she replied, "I don't understand, I just copy it down". I then asked what the ' $x$ ' was on the board, to which she replied "What ' $\mathrm{x}$ '? That's a times." Interpreting letters when they are first met is problematic for many learners (Dickson 1989), as letters can be interpreted in many different ways, sometimes being associated with an object rather than representing a number, whether unknown or variable (Booth 1984). Indeed, one of six categories of letter usage identified by Küchemann (1981) was that of representing an object. MacGregor and Stacey (1997) saw examples of letters being interpreted as an alphabetical code $(a=1, b=2$, etc.), where values of expressions were based upon the order value of the letter within the alphabet. So the introduction of a letter can be problematic and my own experience has been that if attention is placed upon the letter when it is introduced, then this invariably leads to learners questioning what it means and why it is being introduced. As a consequence, in considering tasks with Grid Algebra, I wanted the user's attention to be elsewhere when a letter is introduced.

One key task is trying to re-create a given expression on the grid and a key feature of Grid Algebra is shifting attention from numbers onto operations. This means that within the re-creating task, attention is on which movements/operations are needed and the order of those movements/operations. Little or no attention is on the start number, which is irrelevant to the mathematical challenge. The fact that attention is away from the start number and is placed elsewhere creates the opportunity to introduce a letter while attention is elsewhere. Once learners are used to the recreating task, it can be played again, only this time where the start is not a number but a letter.

Initially, learners might react to a letter being placed in the grid rather than a number. However, if the familiar challenge of re-creating an expression is offered quickly, they recognise the task is essentially the same one that they have been doing previously. The appearance of a letter has no bearing on their ability to complete the task and they soon accept the appearance of a letter (Hewitt 2014b).

Grid Algebra has many computer-generated tasks, one of which is being given an expression and having to re-create that expression on the grid within a given time period. An example of this is shown in Fig. 7, where the task is to re-create the expression $2\left(\frac{a+9}{3}+1\right)-6$ within 30 s. I have found learners very engaged in such activities and the time restraint shifts attention even more onto what is relevant for the task. This means attention is on the operations and the appearance of a letter becomes something which is quickly accepted. 


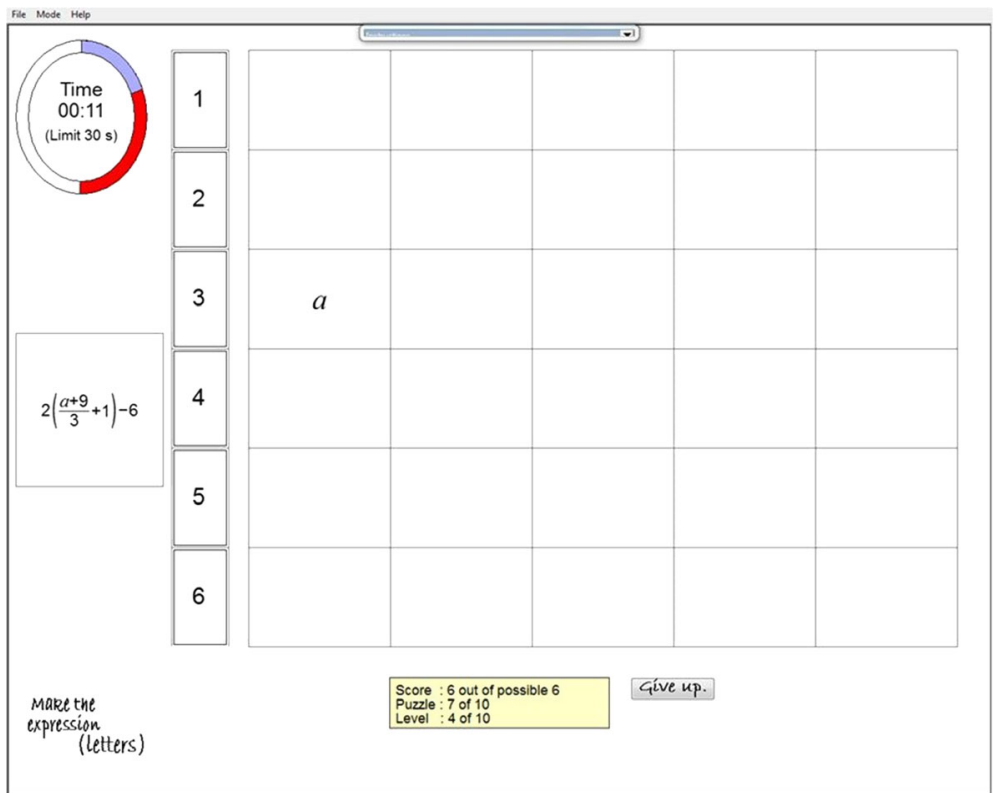

Fig. 7 A computer generated task where the expression has to be re-created within a time period

I will not go into detail here, but there are other tasks where the meaning given for letters can be developed. On an otherwise empty grid, the placement of a letter on to the grid still does not define the grid and the letter can take one of many values (according to which row it has been placed in). This gives a sense of letter as variable. A number can then be dragged from the Number Box and placed into the same cell as the letter, which will then specify the value of that letter. Alternatively, if a number is placed in the same cell as an expression generated from that letter, then an equation such as $3(k+$ $4)-6=42$ is formed. This makes $k$ an unknown and new challenges of trying to find the value of $k$ can begin (more wll be said about the equals sign and solving equations later).

\section{Parsing Expressions}

Standard notation involving the four basic arithmetic operations can appear relatively complex for learners. It involves the use of division lines rather than a division sign, use of brackets, the absence of a multiplication sign, the particular positioning of numbers and operation signs, and rules as to which operations have precedence over other operations. Standard notation has a vertical dimension to it as well as horizontal. Consequently, the order in which is it meant to be read can be a long way from the usual left-to-right scanning used when reading an English text.

The visual journey to unpick the order of operations within the expression $\frac{4\left(\frac{15}{3}+6\right)-8}{2}$ +4 can be seen in Fig. 8. This is far from the usual left-to-right order and teachers as well as learners can have difficulty with correctly reading the order of operations (Glidden 2008). There are acronyms which are used by teachers to help learners remember the order of operations. In the UK, BIDMAS (Brackets Indices Division 


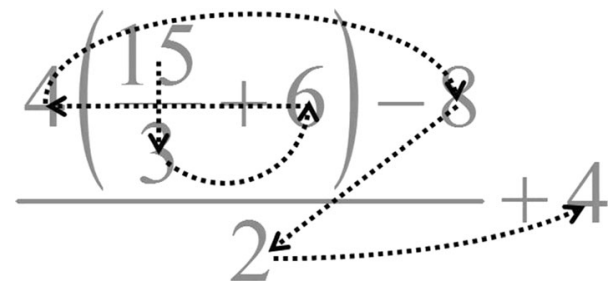

Fig. 8 An example of the visual journey required in order to read formal arithmetic notation

Multiplication Addition Subtraction) is commonly used and, in the USA, PEMDAS (sometimes said as Please Excuse My Dear Aunt Sally) is used to indicate Parentheses Exponents Multiplication Division Addition Subtraction. However, these are also fraught with difficulties, as sometimes the order of $\mathrm{M}$ followed by $\mathrm{D}$ can lead to learners incorrectly thinking that multiplication always has to happen before division and not left-to-right as in the example of $24 \div 2 \times 3$. Or that addition must always take place before subtraction in an expression such as $10-2+3$.

Booth (1984) carried out seminal research which identified many difficulties leaners had with notation. With regard to brackets, for example, she found that learners often ignored them when writing expressions themselves, sometimes due to feeling that the context of the problem they were working on would determine in their own mind the order of operations. Many learners also felt that the same value would be obtained anyway whatever the order of the calculation. Gunnarsson et al. (2012) explored using 'useless' brackets, which were additional brackets included in expressions beyond those which would be required under normal conventions, such as with $2+(4 \times 5)$. These were used as a teaching tool to help learners carry out the correct order of operations. However, they found that in tests carried out with conventionally written expressions, this use of brackets was a hindrance to learners transferring from incorrect straight left-to-right reading of certain expressions to the correct conventional order. They felt that this could be due to the fact that learners were unclear when brackets were an essential part of the convention of reading expressions and when they were being used as an educational device.

I argue that a contributing factor to the difficulty of seeing order of operations within an expression is that the expression exists as a totality within a page. This contrasts with speech, which necessarily happens in time; one word is said before another. There can be difficulties in describing order of operations within speech, but the awareness that time brings with it a natural order is utilised visually within Grid Algebra. The expression $\frac{3\left(\frac{36+12}{2}-4\right)+18}{6}-2$ in Fig. 6 did not just appear all at once. Instead, it was built up one operation at a time, with one movement necessarily happening before the next one. Furthermore, the first movement is the first operation; the second movement, the second operation; etc. Consequently, the expression is gradually seen to build in the order of the operations, so that the final expression has been created gradually over time and in the correct order of operations. Usually, when such an expression is written down, even if a learner were to watch a teacher or fellow learner write the expression, it would usually be written left-to-right as much as possible, with the first number written being ' 3 '. However, with Grid Algebra, the operation ' -4 ', for example, occurs before the 3 appears, since that subtraction takes place before the multiplication. This helps 
learners see the order of operations within the final expression as it has been gradually built up one operation at a time in the order the operations are to be carried out.

The 're-creating an expression' task is key in helping learners to parse expressions. Learners has to look at the structure of the given expression, such as the one above, in order to decide how to move the start number of 36 . Whatever movement they carry out results in the software feeding back the notational consequence of that movement. So, for example, if they felt that they should divide by two first, and then subsequently add 12 , then making the associated moves would result in the expression $\frac{36}{2}+12$. This neutral feedback is informative for learners to see whether they have the order correct, since the visual appearance of $\frac{36}{2}+12$ looks different to the equivalent part of the goal expression. This purely visual feedback is enough for them to judge whether they are interpreting the order of operations correctly (Hewitt 2014b).

Numbers can be entered into the grid by dragging them from the Number Box or entering them through an Expression Calculator. The latter allows an expression to be entered through pressing buttons similar to those found on a calculator. Figure 9a shows a route drawn on the grid. The letter $d$ has already been dragged from a Letter

a

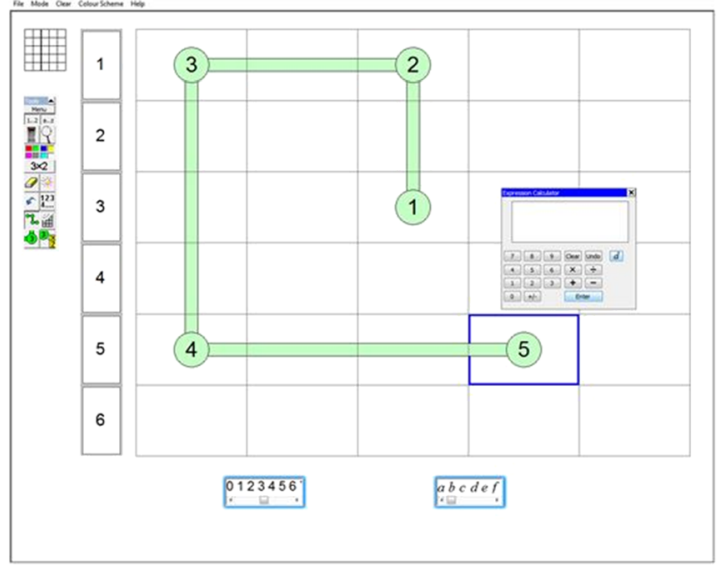

b
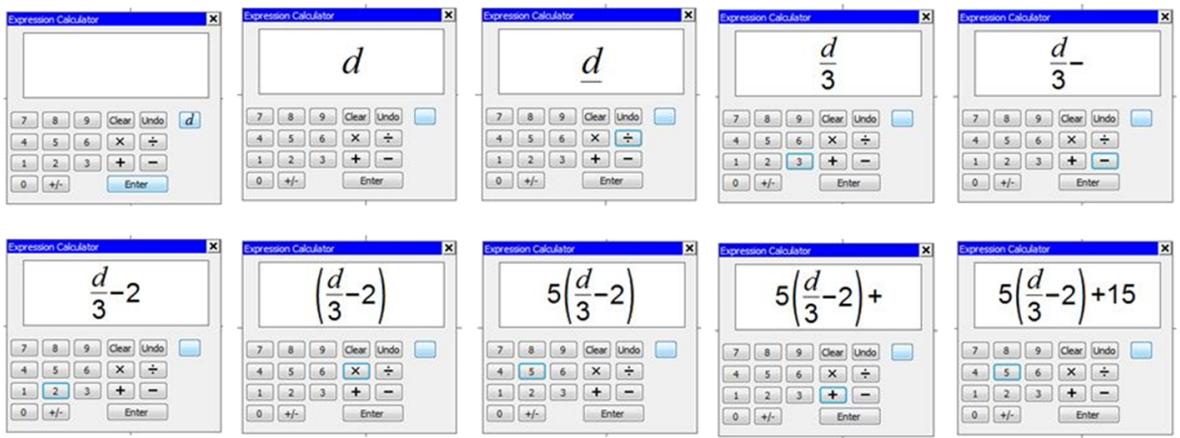

Fig. 9 a The grid where the letter $d$ has already been placed in the start cell of this journey and the task is to enter the final expression, b How the notation appears on the screen after each button press 
Box into the cell at the start of the route (it cannot been seen at present due to the route marker, but if that cell is clicked on, the letter $d$ will appear and that part of the route will temporarily disappear). The Expression Calculator has been put into the final cell of the route and the task is to enter into the calculator the final expression if $d$ were to be taken on that specific journey.

Figure 9b shows what appears inside the Expression Calculator as each button is pressed to create the expression $5\left(\frac{d}{3}-2\right)+15$. There are significant design features within this sequence. Firstly, the expression must be entered in the order of operations and not left-to-right. If someone attempts to start with the number 5 and then presses the $\times$ button, then the Expression Calculator is designed so that the letter $d$ is no longer available on the calculator. Thus, they cannot continue. Pressing the Clear button suddenly brings back the letter $d$ as an optional button to press. So a learner is forced into starting with the letter $d$ since to start with anything else would make the letter $d$ disappear. This is a design choice as the route starts with the letter $d$ and now learners are more likely to attend to the physical journey indicated by the marked route which helps them stay in touch with the order of operations.

After the $d$ button is pressed, the next button pressed is $\div$. However this symbol does not appear on the Expression Calculator screen. Instead, a line appears below the letter $d$ (see Fig. 9b for this and what follows regarding the entering of this whole expression). The fact that one symbol is pressed whilst a different notational symbol appears on the screen helps to associate one with the other. Pressing the 3 button next shows the 3 appearing below the division line. So, the Expression Calculator will show the conventional notation step by step as the operations are entered via the buttons.

The next button pressed is the subtraction button. The significance here is the position of the subtraction sign in relation to the current expression on the screen. The subtraction appears at the same vertical level as the division line and not, as is commonly done by many a learner, at the height of the expression on the top.

After the number 2 is entered, the multiplication sign should next be pressed. As with division, one symbol is pressed but a different symbolism appears on the screen. This time brackets appear. This sets up an association with the act of putting brackets round anything which is not a single symbol when that expression is to be multiplied. In this case, it is going to be multiplied by 5 and, on pressing 5, this number appears to the left of the bracket rather than to its right. So the Expression Calculator will show each symbolic part of the final expression at the same time as each button is pressed; associating mathematical operations with symbolic features and assisting seeing the final expression in the order of operations rather than left-to-right. I will mention other factors which assist the learning of order of operations later on.

\section{Equals Sign}

The final topic I discuss regarding difficulties learners experience concerns the equals sign. This sign is often viewed as a signal to carry out a calculation and place a single symbol afterwards (Behr et al. 1980; Kieran 1981; Linsell and Allan 2010). This is exemplified by learners entering the number 15 into the box in the statement $7+8=\square+9$ (Warren 2003). The use of some calculators can assist this view, as 
pressing the button with the equals sign on it produces the result of a calculation already entered. This operational view of the equals sign does not tend to change between the ages of 11 and 14 and can also affect later performance in solving equation tasks (Knuth et al. 2006). As a consequence, learners sometimes have difficulty when presented with a statement where there is an expression on the right-hand side of the equals sign as well as the left-hand side, such as $7+8=\square+9$ mentioned above.

Carpenter et al. (2003) suggested that there are three types of misconceptions which learners can have when trying to calculate the number which should go into the box: either answer comes next $(7+8=15)$; use all numbers $(7+8+9=24)$; extend the problem $(7+8=15+9=24)$. A more relational view of the equals sign would see learners realising that both expressions either side of the sign are numerically equal. An example of this is the equation $28 \div 7+20=60-36$. However, Cooper et al. (1997) found that about half of a group of 51 Grade 7 learners could not adequately explain what the equals sign meant in this context.

The fact that so many learners have difficulty interpreting the equals sign with a relational meaning may be a consequence of the nature of the way they have been taught. In a comparative study, Li et al. (2008) found that there was a significant difference between Chinese and US Grade 6 students, where a large percentage of US learners appeared to view the equals sign operationally while almost none of the Chinese learners did so. When comparing textbooks, they found that the US ones rarely portray the equals sign relationally, whereas this was very common with the Chinese textbooks. So, the nature of the experiences learners are offered may be significant in the way in which they view the equals sign.

So far in this article, I have not mentioned the equals sign in relation to Grid Algebra activities. The Expression Calculator does not have an equals button. It is used only as a means of entering an expression and does not carry out any calculations. In fact, no tools carry out any calculations within Grid Algebra. More will be said later as to why this is the case. A sense of two expressions being the same comes from the fact that two expressions are in the same cell. For example, in Fig. 4, I talked about making a movement on the grid for the first time. The horizontal movement created the expression $1+1$ and this appears in a cell which previously had the number 2 in it.

Looking again at Fig. 4, you might notice that in the bottom right-hand corner of that cell there is a 'peeled-back corner'. This icon indicates that there is more than one expression in that cell and clicking on that icon will change having $1+1$ in view in that cell to seeing 2 instead. Another click on the icon will return it to $1+1$. In fact, if there are several different expressions within the same cell, each click on the peeled-back corner will cycle round all the expressions one at a time (in the order of the most recently entered). This gives a sense that the 'label' for that cell could be any one of those expressions and hence links the expressions together as having something the same about them. The structure of the grid and the movements which can be made ensure that all expressions in the same cell are numerically or algebraically equivalent.

All expressions within a cell can be seen at the same time through the use of a Magnifier tool. When this tool is selected from the toolbox, and then dropped into a cell, a new small window appears showing all the expressions within that cell connected together through the appearance of equals signs (see Fig. 10). Here, there have been four different routes taken from the $n$ cell to the final cell, resulting in a set of four equivalent expressions. Whichever 


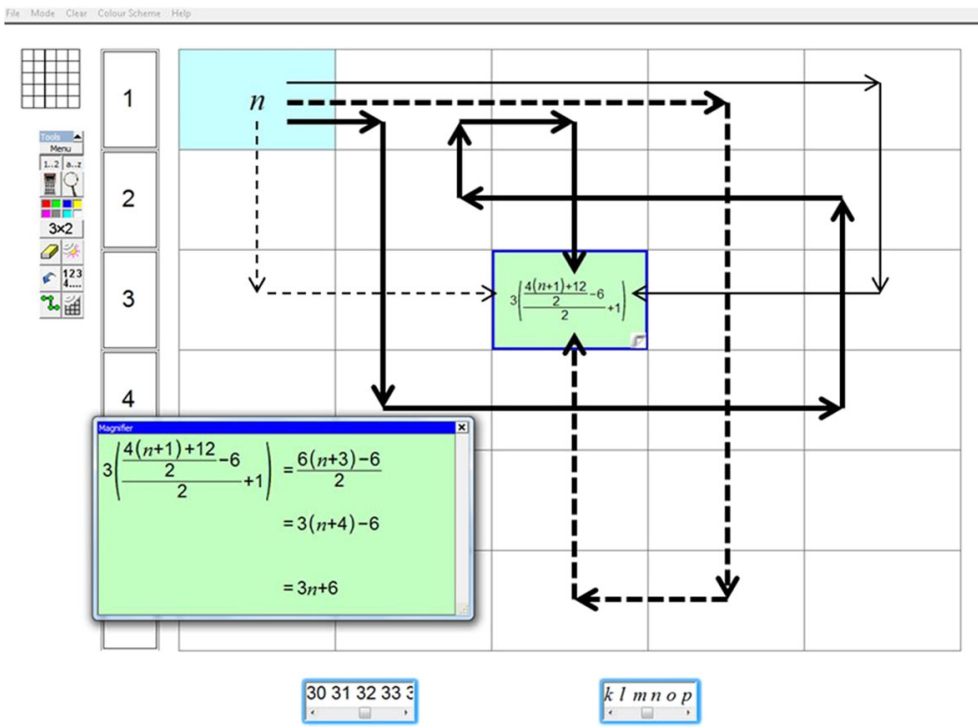

Fig. 10 Different routes taken from the $\mathrm{n}$ cell to another cell with expressions linked by the equals signs

expression is currently on view within the cell is the expression on the left-hand side (LHS) of the top equals sign. All other expressions which appear in the cell are listed on the right-hand side (RHS) of equals signs in the order of most recently entered into the cell down to the expression which first appeared in the cell. However, that order can be changed easily simply by clicking on an expression within the Magnifier window; that expression will then become the expression on the LHS of the top equals sign (and be on view in the cell) with the others appearing on the RHS. By this means, any particular stressing or ordering of expressions can be achieved. This ability to swap expressions from the RHS to the LHS (and vice versa) helps to develop a relational rather than an operational view of the equals sign. Also, within tasks such as the one I describe below, the emphasis is on expressions rather than making a single number the focus of attention, thus reducing the desire to carry out operations.

The mathematical notion of equivalence has an associated notion of making a journey from one particular cell to another. Some journeys are longer than others and consequently those resulting expressions involve more operations than others. Careful choice of journeys can assist learners in gaining awareness of manipulation of expressions. Figure 11 offers an example of an task I call 'I go this way, you go that way' (I go horizontally, then vertically, while you go vertically, then horizontally). The resulting

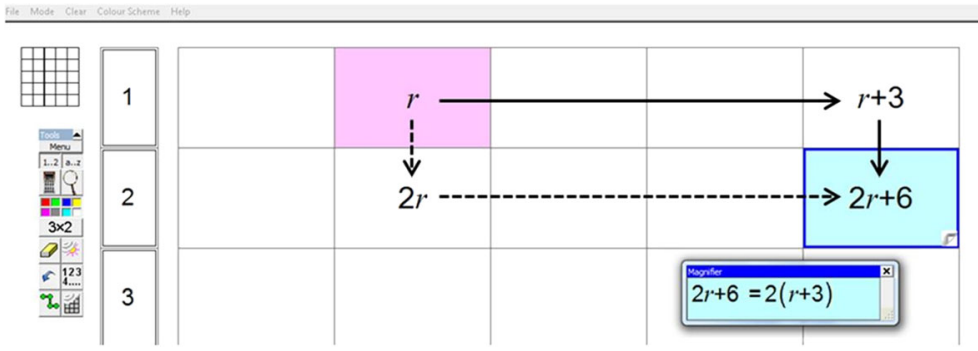

Fig. 11 The task of 'I go this way, you go that way' 
equation of $2 r+6=2(r+3)$ or $2(r+3)=2 r+6$ (since they can easily be swapped round) creates an opportunity to work on the distributive law and factorising. The question Why did it say plus three when I went my way, but it said plus six when you went your way? can be engaged with in two ways: either with reference to the algebraic notation or with reference to the physical journey. The latter allows learners to say that their journey had gone into the two times table first and so moving the three cells to the right means doing three lots of two (as you add two each time in the two times table).

The physical image of moving on the grid supports the mathematical awareness of what happens with the notation, the ' 3 ' being doubled. The supportive image is important initially when someone is beginning to learn, but eventually it is desirable for a learner to be able to multiply out brackets without the support of the grid. Consequently, the design has a built-in facility to shift focus onto the symbols on their own. For example, one of the built-in computer-generated tasks is based upon 'I go this way, you go that way'. Learners have to enter via the Expression Calculator the expression for the alternative route. It gradually withdraws the support of the grid, initially withdrawing the grid whilst keeping the picture of the arrows for the two routes, and then withdrawing even that, so that eventually there is only the expression left (Fig. 12).

The final design issue in this section relates to how different types of expressions can be brought together in the same cell. So far, this has created identities such as $2 r+$ $6=2(r+3)$. However, an expression involving a letter can be created in a cell and then a number can also be entered into that cell, creating an equation with an unknown, such as $2 r+6=32$. This brings the possibility of working on solving equations, which is addressed later. The Letter Box allows different letters to be dragged onto the grid and taken on journeys. If different letters are brought together then equations such as $y=3(x+2)$ can be created. If there are no numbers on the grid, then these letters remain variables. This is because, for example, if the letter $y$ is placed into a cell in the three times table when the rest of the grid is blank, then it can be any multiple of three. If a
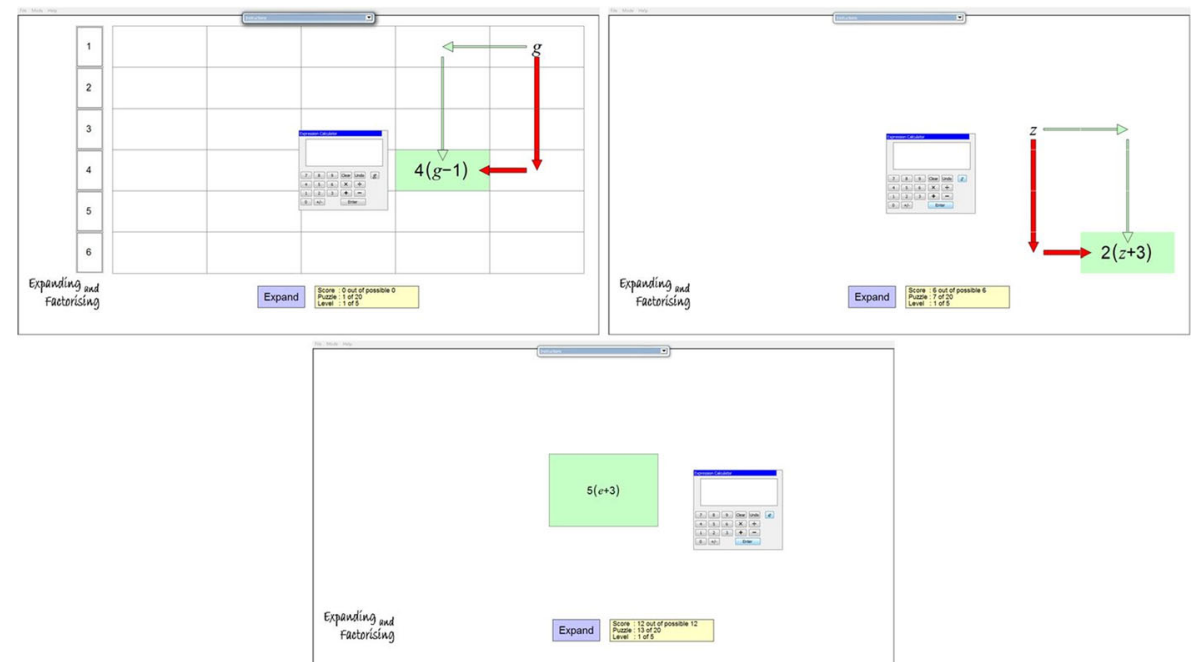

Fig. 12 Expanding brackets task with support of the grid gradually withdrawn, so that learners' attention shifts from the physical journeys on the grid to the mathematical operations in the expression 
number is then put into a cell, then the whole grid is specified and each cell must be a particular number.

This fixing of the grid can also happen when no numbers appear at all. The design allows for the possibility of more than one copy of a particular letter to appear in the cells. Figure 13 shows a series of three screens. The first shows the letter $a$ placed in a cell and at this stage the letter is a variable (note the grid icon at the top-left is empty). The next screen in Fig. 13 has a second copy of the letter $a$ placed in a different cell. Using the convention that occurrences of a single letter stand for the same number, there is just one possibility for the value of $a$ given that it appears in those two particular cells. (Note that now the grid icon is full of numbers, indicating the grid is defined and particular numbers must go into each cell.)

The final screen shows an example of two ways in which these letters can be brought together to create 'clues' for working out the value of $a: 2(a+1)=a-4$ and $a=2(a+3)$. Now only the number -6 would be accepted into either of the cells containing the letter $a$. The design is such that while the first appearance of a particular letter can be placed in any cell, a second and subsequent placing will only be accepted into cells where the forced value of that letter would be an integer, and any additional copies of that letter would then have to be placed in cells which have that same numerical value.
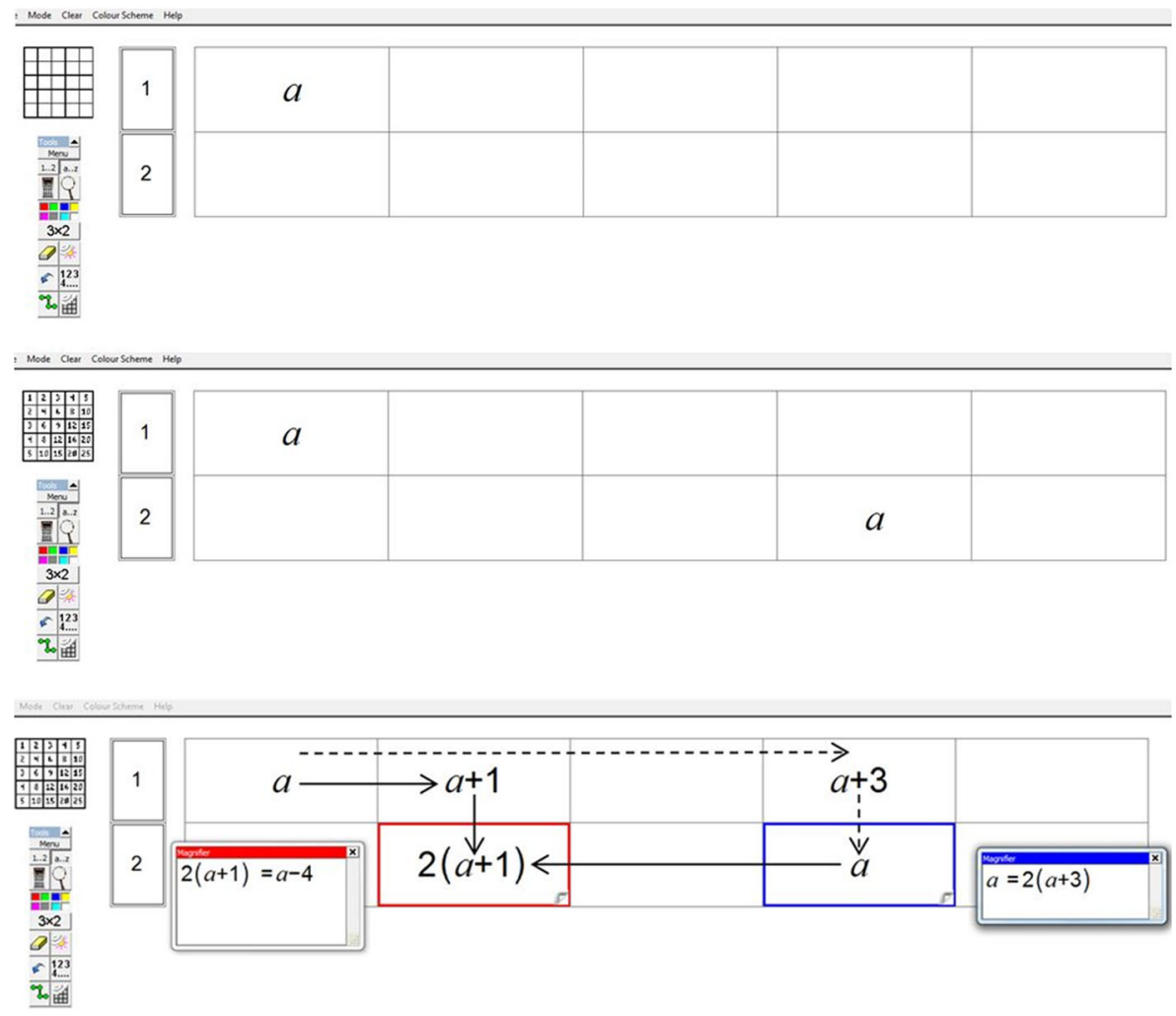

Fig. 13 Three screen shots where the second appearance of the same letter defines the grid (as indicated by the grid icon being full of numbers) and the letter shifts from variable to unknown. In the third screen shot, the letters are brought together in two different ways, each of which acts as a clue to find the value of the letter 


\section{Theoretical Perspectives}

I now discuss three frameworks which are central to the design of the software. These have been left to this part of the article deliberately, so that their influence on the whole design can be seen in the light of knowing many of the key functionings of the software. Two of these frameworks (arbitrary and necessary and subordination) I developed some time ago and they have been central to the design of Grid Algebra. I will address the significance of these in turn below, followed by a discussion of how the third framework (embodied cognition) has also influenced the design.

\section{Arbitrary and Necessary}

Arbitrary and necessary (Hewitt 1999, 2001a, b) divides the mathematics curriculum into those things which are social labels and conventions (the arbitrary) and those which concern properties and relationships (the necessary). The first group of socially agreed labels and conventions include names such as square, five and horizontal. These words have become established over a long period of time and, although there may have been good reasons at the time why each word was adopted, there is nothing necessary about the choice of each particular word. Indeed, in another language, different words are used. So there is nothing about a square which means it has to be called square.

Likewise with conventions that the first number of $(2,3)$ is the $x$ co-ordinate and not the $y$ co-ordinate, or that a whole turn is divided up into 360 when deciding a way to measure turn. There are historical reasons why 360 was chosen that relate to the culture at the time (the Babylonians used a base 60 number system) and mathematical convenience ( 360 has many factors), but that still does not change the fact that there was choice and it did not have to be 360 . As such, for a learner today, these conventions can feel arbitrary. I argue that the focus on the arbitrary for a learner should be one of accepting and adopting, rather than questioning and challenging. Whilst acknowledging that it can be of considerable interest to explore the historical stories of why certain names and conventions were adopted, the focus for a mathematics curriculum is on the adoption and use of the arbitrary in order to work on what is necessary.

Those things which are necessary have to be how they are, given certain arbitrary decisions. There is no choice. So, if we are working with the arbitrary choice of $360^{\circ}$ in a whole turn, then it is necessary that half a turn will have $180^{\circ}$ and reasons can be given for why this must be so. The mathematics lies within the relationship between a whole turn and half a turn rather than the particular numbers involved. Indeed, a similar relationship must occur when talking about radians as much as degrees. The necessary concerns properties and relationships and this is where the mathematics lies.

The equation $2(r+3)=2 r+6$ involves many arbitrary labels and conventions in terms of the symbolism and notation used. However, the relationship is about operations: that if I add three and then double, it gives me the same numerical result as doubling and then adding six. What number I started with is irreverent. This remains true no matter how I might express it notationally. So, suppose a learner were to work on a problem where the task is to find a general rule, such as $2(r+3)$. However, instead of writing this, they write $r+3 \times 2$. What they have written is 'wrong', but what is of importance is to find out what they are wrong about. If they think that the rule is that 
you take $r$ and add to it $3 \times 2$, then they are wrong mathematically, but right notationally. If they think the rule is $r$ add three and then multiply by two, then they are right mathematically, but wrong notationally. The difference is significant for a teacher. In the first case, the leaner's awareness of the mathematical situation needs to be addressed; whereas, in the second case, it is only a matter of helping them adopt a convention about how the rule is written down. The first concerns the necessary and the second, the arbitrary.

Due to its nature, learners cannot know the arbitrary without being informed (Hewitt 1999). So at some point a learner needs to be informed of the names and conventions which are used within the mathematics community. So the role of a teacher is to inform and assist leaners in adopting and using these names and conventions. A teacher's role is quite different for what is necessary. Since the necessary is about properties and relationships, those things for which there are reasons why they have to be how they are, learners can work out these things for themselves. As such, a teacher's role is more concerned with offering appropriate tasks and challenges and using questioning skilfully to assist students in educating their awareness. So a principle I have developed is one of providing the arbitrary while challenging learners to become aware of what is necessary.

Grid Algebra is designed with this principle in mind. The arbitrary is the notation, how expressions are to be written. Grid Algebra provides the standard notation and a learner does not have to know the conventions of arithmetic/algebraic notation in advance of using the software. The notation appears as a consequence of a movement on the grid or as the operations are entered into the Expression Calculator. At the same time, no calculation is performed by the software, nor is any solution to an equation or re-arrangement of an expression carried out. Calculations, solving equations and rearranging expressions concern the necessary and, as such, the software offers challenges related to these within the built-in computer generated tasks.

In addition, the 'Interactive Grid' (which allows teachers and learners to work with the grid in whatever way they wish) offers opportunities for a teacher to set up challenges and use questioning to challenge learners in a way where they are likely to gain new awarenesses about number, operations, expressions and equations (a few of which have been mentioned above). Learning about inverse, order of operations, equivalence of expressions, the distributive law, solving equations, becoming aware of when a letter is an unknown and when a variable, etc., can all be achieved through questioning and challenging learners with appropriate Grid Algebra tasks. While learners are doing this, the software provides what needs to be provided: the notation.

There is a significant advantage to a computer providing the standard notation rather than a teacher. Learners are used to adapting themselves to a technological environment where they have to get used to working with arbitrary things, such as icons, buttonpressing at particular points and combinations of buttons required. I have found that learners may question initially why something is written the way it is, such as why division is written as a fraction rather than with the $\div$ sign or why a multiplication sign is not used. However, there seems to be a quick acceptance that this is how the software writes things, even though it is quite different from what they are used to seeing in their previous years of mathematics lessons (Hewitt 2012).

I have sat in many mathematics lessons where teachers attempt to justify why they are not using the multiplication sign and rarely do I feel that the learners are convinced. 
The question why? is very appropriate for the necessary, but not for the arbitrary. It can lead to a distraction with learners feeling unclear about something before any mathematics is addressed. Learners are often aware of the fact that a teacher has choice and so wonder why the teacher chose to write it in a different way to what which they are familiar. With technology, there is a sense that getting to know the technology will always involve a number of arbitrary things. So learners are more likely to 'accept and adopt' with technology.

\section{Subordination}

When we learn something well, we are often not consciously aware of using that learning when we meet a challenge that requires its use. When I hear the doorbell, I go to the door and see who is there. In doing so, I do not think consciously about what is required from my muscles in order to walk; I do not think about the fact that some dexterity is required to open the door (my door involves pressing a button with my thumb whilst rotating a small lever at the same time). What we use in order to achieve tasks are the things which are being practised. So my typing becomes increasingly fluent because I practise typing not because I want to practise per se, but because there are things I want to write. Dewey (1933) commented that, "the nature of the problem fixes the end of thought, and the end controls the process of thinking" (p. 15; italics in original). As such, it is the task I want to achieve which can determine what it is that I will end up practising.

One feature of these examples is that attention is placed upon achieving the end task and what is practised is something for which I might already have significant fluency. This is sometimes a feature of when fluency has already been achieved: I do not need to pay attention to it. It is often different when someone is still learning something. Then attention is often focused on that which is to be learned. However, I argue that the notion of staying focused upon the end task while learning what is required to achieve that task can be a powerful way in which someone can become fluent, rather than just practising existing fluency. Figure 14 gives a diagrammatic image for subordination (Hewitt 1996) and I use this term when:

(a) a skill or knowing, A, is required to achieve a task, B;

(b) the task, $\mathrm{B}$, does not require $\mathrm{A}$ in order for it to be understood;

(c) a learner can observe and judge the relative success of their attempts at achieving task B;

(d) a learner can adapt and modify their use of A while trying to achieve B.

The first of the above criteria is that $\mathrm{A}$ is required in order to achieve $\mathrm{B}$. This means that there is not an alternative means of achieving B. So, in a teaching context, that might involve the creation of carefully designed rules of what is and is not allowed within a task. Or, with technology, the software is designed so that a learner only has A available to use. The second and third aspect mean that even if learners know little about A, they can still fully understand what the task is and would be able to judge the extent to which they have been successful at this task.

The final aspect means that they can learn from the relative success they are currently having on task B and adapt and modify the way they are using A in order 


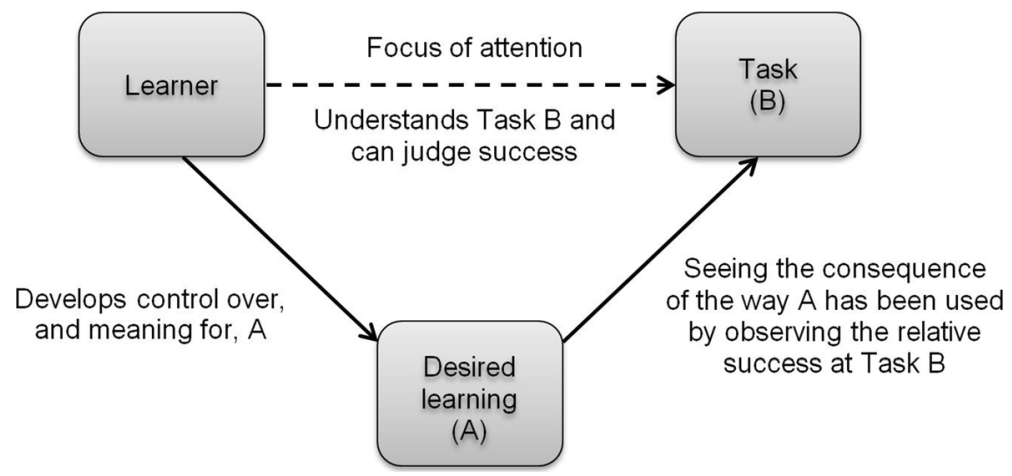

Fig. 14 Subordination: where a learner learns about A through having to use it to achieve B and observing the relative success while so doing

to see whether they can gain better success. Thus, feedback is crucial here. It is seeing the consequences of your actions which inform how your actions are to be modified or adapted in the future. It is this that drives the learning of A. Through attending to the consequences of using A, rather than A itself, a learner becomes more skilled with A.

For example, I may use a hose to wash my car and when I turn on the water supply I can see whether the water is indeed going over my car. If it is not, then I learn about how to use the hose not by looking at the hose but by looking at the car and where the water is going in relation to the car. So attention is on the relative success with the task. This is a relatively unusual feature inside a mathematics classroom, as usually attention is on whatever it is that is being learned. With the use of subordination, attention is on the consequences of the current use of that desired learning upon a specially created task.

A relatively obvious, but nonetheless significant, aspect of the design of Grid Algebra is that the notation is written in a standard form and not in a single-line form such as $36 / 2+12$. There are two aspects to this. Firstly, learners meet and have to work with standard notation and more about this is said below. Secondly, there is an element of what diSessa (1985) has described as naive realism, which is when a learner feels that objects are the visual representations they see on the screen. When a learner moves from one cell to another, they can feel as if they are working directly with the mathematical expression, since the expression is being moved as part of the cell. So learners can feel as if they are directly changing the mathematical expression, such as writing " +2 " onto an expression, when in fact they are just moving a cell to the right.

This sense of working directly with the mathematical notation is important, not only because it is what learners will be doing later when working in more traditional pen and paper contexts, but also because when making movements on the grid they can have intentions of changing the notation in particular ways while gaining feedback from the software about the actual effect on that notation through the actions they took. This relates directly to the notion of subordination, where attention is on the consequences of intended actions. Consider a task which involves an expression, such as $\frac{\frac{2(y-9)+12}{3}+4}{2}$, in a cell in an otherwise empty grid. The task is to find out where the letter $y$ must have been placed in order to have created this expression through movements on the grid. This will require them to find the inverse journey. The challenge of finding where $y$ must 
have been placed can be understood by learners, even if they do not know initially how to go about solving this challenge. They know the end game even if, at present, they do not know the means to achieve that end. Thus, they are forced to pay attention to the symbolic notation and consider inverse in relation to that notation, as this is all they have to work with. This meets the first two conditions for subordination.

The third condition is that a learner can judge the relative success of, in this case, making an inverse journey to get back to where $y$ must have been placed. The present design of the software means that any further movement of that expression would add on an additional operation to the expression. For example, if a learner wanted to do the inverse of divide by two, then they would drag it down in order to multiply by two. However, this would result in a new multiplication occurring in the new expression: $2\left(\frac{\frac{2(y-9)+12}{3}+4}{2}\right)$. This would not be particularly clear feedback for the learner that they had 'undone' the division by two.

So an Inverse button is available in the toolbox. When this is pressed, any movements of an expression will result in the usual extra operation being included within the resultant expression, except when the inverse of the last operation in the expression is carried out. In that case, the last operation is cancelled out and will not appear in the resultant expression. This means that the movement to multiply by two will not result in the expression above, but rather will result in the expression $\frac{2(y-9)+12}{3}+4$. So a learner can judge their relative success through seeing whether their movement does indeed cancel out an operation and simplify the expression. So a sense of getting back to the letter $y$ has a meaning both in terms of taking physical steps on the inverse journey back to where $y$ was and also in terms of taking mathematical steps to reduce the expression so that eventually only the letter $y$ appears.

The nature of the feedback is crucial. For example, a learner may originally think she or he wants to undo the +4 next within the expression $\frac{\frac{2(y-9)+12}{3}+4}{2}$. If they do this by dragging the expression four cells to the left they will see the resultant expression $\frac{\frac{2(y-9)+12}{3}+4}{2}-4$. This will not give them a sense of having simplified the situation and nor having succeeded in cancelling out the +4 . So feedback is offered to learners which does not explicitly say no, this is wrong, but does give them the consequences of their actions (Hewitt 1994) from which they can judge whether they are successfully working towards the end goal.

Typically, this will result in them realising that they need to do something else instead and explore multiplying by two first. This will result in an expression which will confirm that they are getting closer to $y$ (both in terms of the visual expression and also in terms of the physical journey). This design feature relates to what Edwards (1998) describes as interpretable feedback, where expectations are compared with actual outcomes, and means that both the third and fourth condition for subordination is met. So through such tasks, a learner can start off not knowing very much about inverse operations and their order, but can end up learning and becoming quite proficient with finding the inverse operations through having to subordinate this continually to the various tasks at hand. A learner comes to learn without the need for explicit instruction, but rather through continual practice combined with neutral yet highly informative feedback. 
The role of subordination is present within much earlier work with Grid Algebra, including the task mentioned above of trying to re-produce an expression. It is through subordination that learners become familiar and comfortable with formal expressions and learn the order of operations within such expressions, and this is one of the main aims of the software. So often learners are able to find rules in mathematical problems, but have difficulty expressing those rules in standard notation (Swafford and Langrall 2000). Grid Algebra offers a way of starting with standard notation and learning to interpret it correctly through attending to the consequences of the reading of that notation, rather than through explicit instruction. This mirrors how that notation will be used once such learning has become automatised with the focus of the learning being on the completion of given challenges which require the use of that learning rather than on the learning of order of operations as an isolated piece of the curriculum. Thus, learning through subordination reverses Rousseau's (1762/1986) injunction of, "before you can practise an art you must first get your tools" (p. 90). With subordination, learning the tools happens as a consequence of wanting to practise your art.

\section{Embodied Cognition}

Varela et al. (1993) challenged the idea of considering mind and body separately and used the term embodiment to mean "reflection in which body and mind have been brought together" (p. 27). As such, cognition is not seen as something which is separate to "living bodily experience" (Núñez et al. 1999, p. 49). Thinking involves far more than solely a mental activity. It also involves verbal articulations and physical movements, often in the form of gestures (Radford 2011). There has been much interest recently in the role that gestures play in learning mathematics (Arzarello et al. 2009; Cook et al. 2008; Edwards 2009). However, the notion of embodiment goes beyond the idea of learners using their bodies while learning. It is a statement about the fact that all learning, whether cognitive or physical, is rooted within deep experiences which are embedded within us in such a way that it makes no sense to separate out the mind and the body.

Johnson (1987) offers the example of feeling physically balanced, which is a fundamental bodily phenomenon which we all have experienced in one way or another. This is a deeply important sense which relates to other experiences of whether things 'feel right' or whether something is too hot, fast, sharp, noisy, etc. This sense of feeling balanced is also prevalent within mathematical notions such as the use of the equality sign, approximation, equivalence and symmetry. It is fundamentally present within us all as we engage in all sorts of activities, no matter the nature of those activities.

I offer here the example of inverse which is another deeply rooted notion, one embedded in many experiences throughout our lives. If a child moves something and is told to put it back, the movement the child makes is the same distance but in the opposite direction. We have all done this with our arms when pointing and returning to our previous position; we do it when we are walking from one room to another and then return to the original room. The embodied sense of inverse is available to us all when encountering mathematical tasks as much as with any of the physical tasks mentioned above.

Within Grid Algebra the number 4, for example, can be moved three cells to the right and then moved back to its original position. This physical act of returning back to 
where we started is one which is known at a deep level to us all. That does not mean that this is something which a learner might consciously be aware of when engaged in such activity. The fact that it is so deep rooted may, in fact, reduce the likelihood that we pay conscious attention to it. However, we cannot help but bring with us these perceptual-conceptual primitives or image schemas (Johnson 1987; Núñez et al. 1999) to whichever tasks in which we engage.

So learners bring with them their sense of inverse and making such a journey will fit in with the idea that the second movement was the inverse of the first and that they have returned to the same place. This is supported symbolically by the equation $4+3-3=4$ which reflects both the inverse nature of the operations and the fact that they are back at the number 4 where they started. So +3 and -3 can be felt in a bodily sense as inverse to each other and seen as inverse operations within the resulting expression. The perceptual-conceptual primitive of inverse supports the engagement in what is happening regarding the mathematical operations and symbolic notation.

Another design feature involves the physical movements themselves. Sometimes a learner wants to move diagonally from one cell to another. However, only horizontal or vertical movements are allowed, so that there is a direct relationship between one physical movement and one mathematical operation. Even if someone wants to carry out two consecutive additions, for example to move the letter $x$ in row 1 (to produce $x+$ $3+1$ ), they have to click on the mouse and drag the letter $x$ along three cells, then they must release the mouse button, before clicking again to pick up the new $x+3$ to drag it one more cell to the right. Thus, to create two operations involves making two distinct physical movements, so that someone feels two movements when two operations are carried out. This helps establish a close link between physical acts and the resultant mathematical symbolism.

Many journeys, such as walking from home to a local shop, involve multiple changes in direction and we are all used to the fact that in doing the inverse journey along the same route involves a reverse order of those directions. So the notion and significance of order is also wrapped up in the perceptual-conceptual primitive of inverse. Figure 15 shows the letter $x$ being taken on a journey involving multiple directions in order to create an expression. The number 56 is then put into the same cell as the expression to create the equation $4\left(\frac{2 x-12}{6}-1\right)=56$. Then the embodied sense of inverse takes the number 56 and moves it backwards along the same route, but in the opposite direction, to arrive back at the letter $x$. The design of the software is such that the intuitive sense of carrying out the inverse journey physically along the same route is reflected symbolically by carrying out the inverse operations in order to solve the equation, resulting in $x=\frac{6\left(\frac{56}{4}+1\right)+12}{2}$.

diSessa (1985) writes of a spatial metaphor, wanting "to tap the well-developed pool of knowledge about space that humans already possess" (p. 4) within the design of educational software. Grid Algebra does this in terms of our experience of making journeys. The design of the software allows a teacher to "teach from embodied understandings" (Davis 1996, p. 239), where learners can intuitively get a sense of how to solve an equation as it runs alongside their intuitive notions of order and inverse. The solving of an equation feels like a natural process rather than a set of rules they have been told to do and have to try to remember. The software allows gradual fading of support, as in Fig. 12, so that learners end up solving equations with only the 


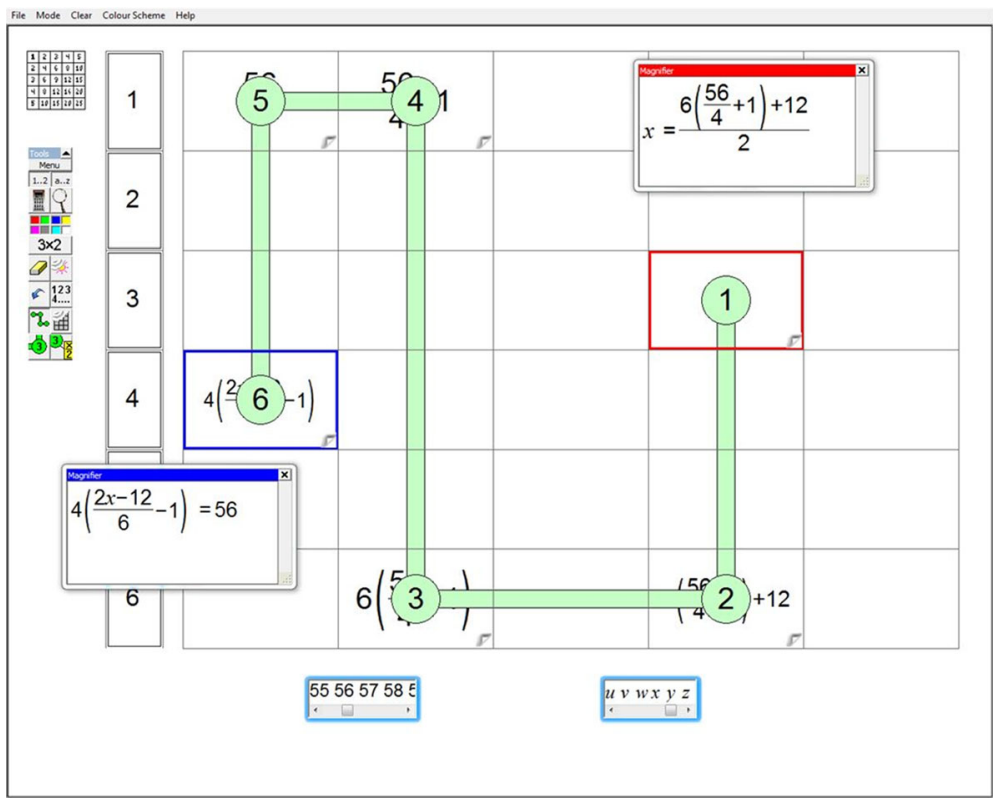

Fig. 15 A journey from $x$ to create an equation and the inverse journey along the same route which solves that equation

symbolic equations to work with, mirroring what they are required to do with pencil and paper.

There are other ways, which I will not elaborate on here, where the design of Grid Algebra utilises other primitives to support mathematical activity. Equivalence, for example, builds upon the primitive of knowing that there is usually more than one way to go from one place to another. The equivalence lies in the fact that alternative routes all start and finish in the same place. The resultant expressions of such routes created in Grid Algebra will result in equivalent expressions. The notion of 'simplifying' connects to the idea of choosing a simpler route from one cell to another from all the possible routes. Such a 'simpler' route results in a 'simpler' expression.

\section{Final Remarks}

The design of Grid Algebra has been based upon the frameworks of arbitrary and necessary, where only the arbitrary notation is produced by the software while the necessary mathematical properties and relationships come from engagement with carefully designed tasks. The design stresses placing attention on operations rather than numbers through the dynamic movement which is possible on the grid. The embodied nature of carrying out physical movements is associated with carrying out mathematical operations through the consequences of movements being fed back in terms of mathematical operations written in standard notation. The fact that standard notation is the only thing which is created on the grid, means that this is subordinated to any challenges offered, such as re-creating an expression or trying to solve an equation. 
The notion of subordination means that learners become confident and fluent with standard notation relatively quickly. Indeed, learners often relish making quite complex expressions, involving ten or more operations, whereas teachers are traditionally more inclined to use much simpler expressions. Learners also come to show confidence in dealing with these complex expressions. The bodily experience all learners have had with making journeys, and then making return journeys, means that these life experiences support the new awareness of identifying which mathematical operations are involved in solving equations, and in which order. As such, much of this early algebra learning can become intuitive.

Some of the well-established difficulties that learners often experience with learning algebra have been considered within the design: expressions are treated as much as objects as they are as processes; the equals sign is not treated as an indicator to provide a single numerical answer; the parsing of expressions is quickly learnt through the subordination of those expressions to carefully designed tasks; due to attention being on operations, a letter can be introduced and accepted with relatively little fuss.

All metaphors and analogies used as pedagogical tools have their limitations as well as strengths. David Wheeler (1996) commented that, "a pedagogical device can be too noisy, too full of distractions, to achieve its objective" (p. 324). Indeed, with Grid Algebra, there is 'noise' and the software does have limitations. I list here some of them:

- students need to remember with which direction each operation is associated (although I feel it takes little time for learners to become familiar with this);

- the number of rows dragged down in order to multiply an expression by two, for example, varies according to the row in which the start expression appears;

- there was a pedagogic choice made when designing the grid that only whole numbers be involved: although the reasons for this are significant pedagogically, it means that students do not experience working with expressions which contain fractional or decimal numbers;

- not all linear expressions are possible within Grid Algebra - for example, $3 x+2-x$ is not possible: I did consider ways in which such expressions could be created, but felt this created far too much extra 'noise' to be worth the educational benefit it might bring;

- expressions with powers are not possible;

- although equations with $x$ on both sides are possible to create, Grid Algebra does not offer a way of operating directly upon either of those letters.

So Grid Algebra has many limitations. However, it also offers a highly intuitive way in which learners can become confident with many keys aspects of beginning work on algebra, including:

- becoming familiar and confident with formal notation;

- interpreting order of operations within relatively complex expressions;

- becoming used to the inclusion of letters in expressions and substituting values for those letters;

- multiplying out brackets and factorising expressions;

- generating equivalent expressions; 
- working out inverse operations for a given expression;

- solving a sub-set of linear equations.

Many of the above come with a sense of generality, where learners' developing awareness goes beyond the limitations of the precise expressions possible within Grid Algebra. For example, I have found (see Hewitt 2014a) that equivalent questions given within a pencil-and-paper environment only were answered just as successfully as those completed within a Grid Algebra environment and that learners were subsequently able to work successfully with linear expressions which were not possible within a Grid Algebra environment. The generality, for example, of carrying out inverse operations can be utilised with an $x$ in the equation $4 x+12=16+x$ to produce $4 x+12-x=16$ just as it can with the 8 in $4 x+12=16+8$ to produce $4 x+12-8=16$. So, although the former manipulation cannot be done within the Grid Algebra environment, the generality learned within the software environment carries over to situations outside the environment.

It is also worth noting that any resource is designed to be helpful for certain mathematical notions and that no resource can deal with all of mathematics. As diSessa (1985) has suggested, there is a "possibility, even the necessity, of using different models for different purposes and of a gradual shift in the kind of model employed as a user becomes more experienced" (p. 3). Grid Algebra provides certain key foundations for algebra in an intuitive way. Those can then be applied within new learning situations, possibly with the use of different models to develop further learning of algebra.

This article has identified some of the key ideas with which Grid Algebra has been designed. While accepting that there are educational limitations contained within the functionality of the software, the design nonetheless allows learners to engage with the beginning of algebra in a more intuitive way than is common within more traditional approaches to this 'hard-to-teach' topic in a way which also tries to redress some of the known difficulties many learners experience when learning in a more traditional way.

Several issues came to mind from the process of designing Grid Algebra, some specific to the software and others more generally. I will finish with these questions:

- Was the decision to restrict expressions to include only whole numbers a correct one?

Rather than a move straight from the second to the third row not being allowed, the notation consequence could have been expressed as: $\frac{3}{2}$ (expression). There is a balance between opening up new possibilities for expressions and not wanting some notation to appear to which a learner might struggle to relate.

- There could be ways in which a general, $n$ th, row is shown and would allow expressions such as $2 n+3 n$ by staring with 2 in row 1 , dragging down to the $n$th row, and then moving three cells to the right. This would allow a letter to appear more than once within an expression, but adds a whole new complexity in terms of the visual environment as well as the rules as to what can or cannot be done between other rows and the $n$th row. Should this facility have been included?

This is an example of where a designer needs to consider whether something which is technically possible is educationally desirable. Metaphorical images and resources for mathematics can offer support for a learner, but what equally is 
important is that the learner is learning mathematics and not just learning the resource. As such, a learner needs to see the mathematics through the resource and not just see the resource alone.

- How might a teacher work with resources which respect the tenet that learners be informed only of the arbitrary while they work on what is necessary?

- What other educational resources can tap into the notion of embodiment, so that learners can engage with mathematics in an intuitive way?

- What other technological environments can employ the notion of subordination, in order to assist learners in gaining fluency with certain areas of mathematics?

\section{References}

Ainley, J. (1999). Doing algebra-type stuff: emergent algebra in the primary school. In O. Zaslavsky (Ed.), Proceedings of the 23rd PME conference (Vol. 2, pp. 9-16). Haifa, IL: International Group for the Psychology of Mathematics Education.

Arzarello, F., Paola, D., Robutti, O., \& Sabena, C. (2009). Gestures as semiotic resources in the mathematics classroom. Educational Studies in Mathematics, 70(2), 97-109.

Behr, M., Erlwanger, S., \& Nichols, E. (1980). How children view the equals sign. Mathematics Teaching, 92, $13-15$.

Bills, L., Ainley, J., \& Wilson, K. (2006). Modes of algebraic communication: moving from spreadsheets to standard notation. For the Learning of Mathematics, 26(1), 41-47.

Booth, L. (1984). Algebra: children's strategies and errors. Windsor, UK: NFER-Nelson.

Brizuela, B., \& Schliemann, A. (2004). Ten-year-old students solving linear equations. For the Learning of Mathematics, 24(2), 33-40.

Caglayan, G., \& Olive, J. (2010). Eighth grade students' representations of linear equations based on a cups and tiles model. Educational Studies in Mathematics, 74(2), 143-162.

Carpenter, T., Franke, L., \& Levi, L. (2003). Thinking mathematically: integrating arithmetic and algebra in elementary school. Portsmouth, NH: Heinemann.

Carraher, D., Schliemann, A., \& Brizuela, B. (2001). Can young students operate on unknowns? In M. van den Heuvel-Panhuizen (Ed.), Proceedings of the 25th PME conference (Vol. 1, pp. 130-140). Utrecht, NL: International Group for the Psychology of Mathematics Education.

Cook, S., Mitchell, Z., \& Goldin-Meadow, S. (2008). Gesturing makes learning last. Cognition, 106(2), 10471058.

Cooper, T., Boulton-Lewis, G., Atweh, B., Pillay, H., Wilss, L., \& Mutch, S. (1997). The transition from arithmetic to algebra: initial understanding of equals, operations and variable. In E. Pekhonen (Ed.), Proceedings of the 21st PME conference (Vol. 2, pp. 89-96). Lahti, FI: International Group for the Psychology of Mathematics Education.

da Rocha Falcao, J. (1995). A case study of algebraic scaffolding: from balance scale to algebraic notation. In L. Meira \& D. Carraher (Eds.), Proceedings of the 19th PME conference (Vol. 2, pp. 66-73). Recife, BR: International Group for the Psychology of Mathematics Education.

Davis, B. (1996). Teaching mathematics: toward a sound alternative. New York, NY: Garland Publishing.

DES. (1982). Mathematics counts. London, UK: HMSO.

Dewey, J. (1933). How we think: a restatement of the relation of reflective thinking to the educative process (2nd ed.). Lexington, MA: D.C. Heath and Co.

Dickinson, P., \& Eade, F. (2004). Using the number line to investigate the solving of linear equations. For the Learning of Mathematics, 24(2), 41-47.

Dickson, L. (1989). Equations. In D. Johnson (Ed.), Children's mathematical frameworks 8-13 (pp. 151-190). Windsor, UK: NFER-Nelson.

diSessa, A. (1985). A principled design for an integrated computational environment. Human-Computer Interaction, 1(1), 1-47.

Dörfler, W. (2006). Inscriptions as objects of mathematical activities. In J. Maasz \& W. Schloeglmann (Eds.), New mathematics education research and practice (pp. 97-111). Rotterdam, NL: Sense Publishers. 
Edwards, L. (1998). Embodying mathematics and science: microworlds as representations. Journal of Mathematical Behavior, 17(1), 53-78.

Edwards, L. (2009). Gestures and conceptual integration in mathematical talk. Educational Studies in Mathematics, 70(2), 127-141.

Falle, J. (2007). Students' tendency to conjoin terms: an inhibition to their development of algebra. In J. Watson \& K. Beswick (Eds.), Proceedings of the 30th MERGA conference (Vol. 1, pp. 285-294). Hobart, AU: Mathematics Education Research Group of Australasia.

Filloy, E., \& Rojano, T. (1989). Solving equations: the transition from arithmetic to algebra. For the Learning of Mathematics, 9(2), 19-25.

Freudenthal, H. (1973). Mathematics as an educational task. Dordrecht, NL: Reidel.

Gattegno, C. (1988). The science of education part 2b: the awareness of mathematization. New York, NY: Educational Solutions.

Glidden, P. (2008). Prospective elementary teachers' understanding of order of operations. School Science and Mathematics, 108(4), 130-136.

Gray, E., \& Tall, D. (1994). Duality, ambiguity and flexibility: a proceptual view of simple arithmetic. Journal for Research in Mathematics Education, 25(2), 115-141.

Greeno, J. (1994). Gibson's affordances. Psychological Review, 101(2), 336-342.

Gunnarsson, R., Hernell, B., \& Sönnerhed, W. (2012). Useless brackets in arithmetic expressions with mixed operations. In T. Tso (Ed.), Proceedings of the 36th PME conference (Vol. 2, pp. 275-282). Taipei, TW: International Group for the Psychology of Mathematics Education.

Herscovics, N., \& Linchevski, L. (1994). A cognitive gap between arithmetic and algebra. Educational Studies in Mathematics, 27(1), 59-78.

Hewitt, D. (1994). The principle of economy in the teaching and learning of mathematics. Unpublished PhD dissertation. Milton Keynes, UK: The Open University.

Hewitt, D. (1996). Mathematical fluency: the nature of practice and the role of subordination. For the Learning of Mathematics, 16(2), 28-35.

Hewitt, D. (1999). Arbitrary and necessary: a way of viewing the mathematics curriculum. For the Learning of Mathematics, 19(3), 2-9.

Hewitt, D. (2001a). Arbitrary and necessary: part 2 assisting memory. For the Learning of Mathematics, 21(1), 44-51.

Hewitt, D. (2001b). Arbitrary and necessary: part 3 educating awareness. For the Learning of Mathematics, 21(2), 37-49.

Hewitt, D. (2012). Young students learning formal algebraic notation and solving linear equations: are commonly experienced difficulties avoidable? Educational Studies in Mathematics, 81(2), 139-159.

Hewitt, D. (2014a). The space between the unknown and a variable. In P. Liljedahl, S. Oesterle, C. Nicol, \& D. Allan (Eds.), Proceedings of the 38th PME conference (Vol. 3, pp. 289-296). Vancouver, BC: International Group for the Psychology of Mathematics Education.

Hewitt, D. (2014b). A symbolic dance: the interplay between movement, notation, and mathematics on a journey toward solving equations. Mathematical Thinking and Learning, 16(1), 1-31.

Johnson, M. (1987). The body in the mind: the bodily basis of meaning, imagination and reason. Chicago, IL: University of Chicago Press.

Kieran, C. (1981). Concepts associated with the equality symbol. Educational Studies in Mathematics, 12(3), 317-326.

Kirshner, D. (1989). The visual syntax of algebra. Journal for Research in Mathematics Education, 20(3), 274-287.

Knuth, E., Stephens, A., McNeil, N., \& Alibali, M. (2006). Does understanding the equal sign matter? Evidence from solving equations. Journal for Research in Mathematics Education, 37(4), 297-312.

Koedinger, K., Alibali, M., \& Nathan, M. (2008). Trade-offs between grounded and abstract representations: evidence from algebra problem solving. Cognitive Science, 32(2), 366-397.

Küchemann, D. (1981). Algebra. In K. Hart (Ed.), Children's understanding of mathematics: 11-16 (pp. 102119). London, UK: John Murray.

Li, X., Ding, M., Capraro, M., \& Capraro, R. (2008). Sources of differences in children's understandings of mathematical equality: comparative analysis of teacher guides and student texts in china and the united states. Cognition and Instruction, 26(2), 195-217.

Linsell, C., \& Allan, R. (2010). Prerequisite skills for learning algebra. In M. Pinto \& F. Kawasaki (Eds.), Proceedings of the 34th PME conference (Vol. 3, pp. 217-224). Belo Horizonte, BR: International Group for the Psychology of Mathematics Education.

MacGregor, M., \& Stacey, K. (1997). Students' understanding of algebraic notation: 11-15. Educational Studies in Mathematics, 33(1), 1-19. 
McNeil, N., \& Alibali, M. (2005). Why don't you change your mind? Knowledge of operational patterns hinders learning and performance on equations. Child Development, 76(4), 883-899.

Núñez, R., Edwards, L., \& Matos, J. (1999). Embodied cognition as grounding for situatedness and context in mathematics education. Educational Studies in Mathematics, 39(1-3), 45-65.

Radford, L. (2002). The seen, the spoken and the written: a semiotic approach to the problem of objectification of mathematical knowledge. For the Learning of Mathematics, 22(2), 14-23.

Radford, L. (2011). Embodiment, perception and symbols in the development of early algebraic thinking. In B. Ubuz (Ed.), Proceedings of the 35th PME conference (Vol. 4, pp. 17-24). Ankara, TR: International Group for the Psychology of Mathematics Education.

Rousseau, J.-J. (1762/1986). Émile. London, UK: Dent.

Sáenz-Ludlow, A., \& Walgamuth, C. (1998). Third graders' interpretations of equality and the equal symbol. Educational Studies in Mathematics, 35(2), 153-187.

Sfard, A. (1991). On the dual nature of mathematical conceptions: reflections on processes and objects as different sides of the same coin. Educational Studies in Mathematics, 22(1), 1-36.

Sfard, A., \& Linchevski, L. (1994). The gains and pitfalls of reification: the case of algebra. Educational Studies in Mathematics, 26(2-3), 191-228.

Steffe, L., \& Olive, J. (1996). Symbolizing as a constructive activity in a computer microworld. Journal of Educational Computing Research, 14(2), 113-138.

Swafford, J., \& Langrall, C. (2000). Grade 6 students' pre-instructional use of equations to describe and represent problem situations. Journal for Research in Mathematics Education, 31(1), 89-112.

Tahta, D. (1981). Some thoughts arising from the new Nicolet films. Mathematics Teaching, 94, $25-29$.

Tall, D. (1991). Reflections. In D. Tall (Ed.), Advanced mathematical thinking (pp. 251-259). Dordrecht, NL: Kluwer Academic Publishers.

Tall, D., \& Thomas, M. (1991). Encouraging versatile thinking in algebra using the computer. Educational Studies in Mathematics, 22(2), 125-147.

Varela, F., Thompson, E., \& Rosch, E. (1993). The embodied mind: cognitive science and human experience. Cambridge, MA: The MIT Press.

Vlassis, J. (2002). The balance model: hindrance or support for the solving of linear equations with one unknown. Educational Studies in Mathematics, 49(3), 341-359.

Warren, E. (2003). Young children's understanding of equals: A longitudinal study. In N. Pateman, B. Dougherty \& J. Zilliox (Eds), Proceedings of the 27th PME conference (pp. 379-387). Hawai'i, HI: International Group for the Psychology of Mathematics Education.

Warren, E. (2006). Teacher actions that assist young students write generalizations in words and in symbols. In J. Novotná, H. Moraová, M. Krátká, \& N. Stehliková (Eds.), Proceedings of the 30th PME conference (Vol. 5, pp. 377-384). Prague, CZ: International Group for the Psychology of Mathematics Education.

Wheeler, D. (1996). Reflections on different approaches to algebra. In N. Bednarz, C. Kieran, \& L. Lee (Eds.), Approaches to algebra. Perspectives for research and teaching (pp. 317-325). Dordrecht, NL: Kluwer Academic Publishers. 